\title{
Characteristics of gliomas in patients with somatic IDH mosaicism
}

\author{
Charlotte Bonnet ${ }^{1,2,3}$, Laure Thomas ${ }^{1}$, Dimitri Psimaras ${ }^{4}$, Franck Bielle ${ }^{5,6,7,8}$, Elodie Vauléon ${ }^{9}$, Hugues Loiseau ${ }^{10}$, \\ Stéphanie Cartalat-Carel ${ }^{1}$, David Meyronet ${ }^{2,3,11}$, Caroline Dehais ${ }^{3}$, Jérôme Honnorat ${ }^{1,2,12}$, Marc Sanson ${ }^{4,6,7,8}$ \\ and François Ducray ${ }^{1,2,3^{*}}$
}

\begin{abstract}
IDH mutations are found in the majority of adult, diffuse, low-grade and anaplastic gliomas and are also frequently found in cartilaginous tumors. Ollier disease and Maffucci syndrome are two enchondromatosis syndromes characterized by the development of multiple benign cartilaginous tumors due to post-zygotic acquisition of IDH mutations. In addition to skeletal tumors, enchondromatosis patients sometimes develop gliomas. The aim of the present study was to determine whether gliomas in enchondromatosis patients might also result from somatic IDH mosaicism and whether their characteristics are similar to those of sporadic IDH-mutated gliomas. For this purpose, we analyzed the characteristics of 6 newly diagnosed and 32 previously reported cases of enchondromatosis patients who developed gliomas and compared them to those of a consecutive series of 159 patients with sporadic IDH-mutated gliomas. As was the case with sporadic IDH mutated gliomas, enchondromatosis gliomas were frequently located in the frontal lobe (54\%) and consisted of diffuse low-grade (73\%) or anaplastic gliomas (21\%). However, they were diagnosed at an earlier age ( 25.6 years versus 44 years, $p<0.001$ ) and were more frequently multicentric ( $32 \%$ versus $1 \%, p<0.001$ ) and more frequently located within the brainstem than sporadic IDH mutated gliomas (21\% versus $1 \%$, $p<0.001)$. Their molecular profile was characterized by IDH mutations and loss of ATRX expression. In two patients, the same IDH mutation was demonstrated in the glioma and in a cartilaginous tumor. In contrast to sporadic IDH mutated gliomas, no enchondromatosis glioma harbored a 1 p/19q co-deletion ( $0 / 6$ versus $59 / 123, p=0.03$ ). The characteristics of gliomas in patients with enchondromatosis suggest that these tumors, as cartilaginous tumors, result from somatic IDH mosaicism and that the timing of IDH mutation acquisition might affect the location and molecular characteristics of gliomas. Early acquisition of IDH mutations could shift gliomagenesis towards the brainstem thereby mimicking the regional preference of histone mutated gliomas.
\end{abstract}

Keywords: IDH mutation, Glioma, Somatic mosaicism, Ollier, Maffucci

\section{Introduction}

Mutations in the IDH1 or IDH2 genes are found in the majority of adult diffuse grade II and grade III gliomas and are considered as the earliest oncogenic event in these tumors [50]. These mutations result in the abnormal production of 2-hydroxyglutarate (2-HG) which is structurally similar to alpha-ketoglutarate. 2-HG competitively inhibits multiple alpha-ketoglutarate enzymes leading to histone and DNA hypermethylation, altered cell differentiation,

\footnotetext{
* Correspondence: francois.ducray@chu-lyon.fr

${ }^{1}$ Hospices Civils de Lyon, Hôpital Neurologique, Service de Neuro-oncologie, 59 Bvd Pinel, 69394 Lyon, Cedex, France

${ }^{2}$ Université Claude Bernard Lyon 1, Lyon, France

Full list of author information is available at the end of the article
}

activation of enzymes implicated in HIF degradation and PDGFRA overexpression [14, 26, 30,47]. In addition to gliomas, $I D H$ mutations are particularly frequent in cartilaginous tumors $[2,50]$. Ollier disease and Maffucci syndrome are two rare non-hereditary enchondromatosis syndromes characterized by the development of multiple benign cartilaginous tumors (enchondromas). Enchondromas appear during childhood and may progress to chondrosarcomas in up to $30 \%$ of cases [3, 36]. In Maffucci syndrome, enchondromas are associated with soft tissue hemangiomas. The analysis of $I D H$ mutations in multiple cartilaginous tumors and non-neoplastic tissues from enchondromatosis patients led to the conclusion that these pathologies are due to early post-zygotic acquisition 
of $I D H$ mutations, resulting in somatic mosaic mutations of $I D H 1$ or $I D H 2[3,36]$. In addition to skeletal tumors, enchondromatosis patients may develop other neoplasm including juvenile granulosa tumors, cholangiocarcinomas, pituitary adenomas, acute myeloid leukemia and gliomas. The aim of the present study was to determine whether gliomas in enchondromatosis patients might also result from somatic $I D H$ mosaicism and whether their characteristics are similar to those of sporadic $I D H$-mutated gliomas. For this purpose, we analyzed the characteristics of 6 newly diagnosed and 32 previously reported cases of enchondromatosis patients who developed gliomas, and compared them to those of a consecutive series of 159 patients with sporadic $I D H$-mutated gliomas.

\section{Materials and methods}

We retrospectively reviewed the medical and radiological records of 6 patients with Ollier disease $(n=5)$ or Maffucci syndrome $(n=1)$ who were referred to our neuro-oncology departments (Pitié-Salpêtière Hospital in Paris, Hospices Civils of Lyon, CHU of Bordeaux and Rennes) for the diagnosis of glioma, as well as 159 consecutive patients who were diagnosed with an IDH1 or IDH2 mutated sporadic glioma between 2010 and 2014 (Hospices Civils of Lyon). Multicentric gliomas were defined as multiple gliomas without connecting T2/FLAIR signal abnormality and distinguished from multifocal gliomas (i.e. multiple gliomas with connecting T2/FLAIR signal abnormality) [1]. IDH mutations and $1 \mathrm{p} / 19 \mathrm{q}$ codeletion status were determined based on DNA extracted from blood and FFPE tumor using a standard protocol (Qiagen, QIAmp DNA mini Kit). IDH1 codon 132 and $I D H 2$ codon 172 were sequenced using the Sanger method with the following primers: IDH1Forward: TGTGTTGAGATGGACGCCTATTTG; IDH1Reverse: TGCCACCAACGACCAAGTC; IDH2-Forward: GCCCGGTCTGCCACAAAGTC and IDH2-Reverse: TT GGCAGACTCCAGAGCCCA, as previously reported [21]. The $1 \mathrm{p} / 19 \mathrm{q}$ co-deletion was determined based on the loss of heterozygosity technique (LOH) using microsatellite polymorphism markers as previously described [18]. In 3 patients, $1.5 \mu \mathrm{g}$ of DNA extracted from frozen tumor tissue was outsourced to Integragen Company for the determination of the genomic profile based on Illumina SNP arrays [22]. In enchondromatosis gliomas, immunohistochemistry was performed on $4 \mu \mathrm{m}$ thick sections of formalin-fixed paraffin embedded blocks with a Ventana Benchmark XT Device. The following antibodies were used after antigen retrieval to assess the expression of ATRX (anti-ATRX, Sigma, polyclonal, dilution 1/400), IDH1R132H (anti-IDH1R132H, Dianova, clone H09, dilution 1/50) and TP53 (clone DO.7, Dako, dilution $1 / 200$ ). Previously reported cases of patients with Ollier disease or Maffucci syndrome who developed gliomas were identified through PubMed searches from January 1970 until September 2015 using the terms "Ollier disease", "Maffucci syndrome", "glioma" and "brain tumor". We retrieved all relevant articles and checked additional references quoted in these articles. Categorical comparisons were performed using Fisher's exact test and a t-test was used for quantitative variables. The threshold for statistical significance was $p=0.05$.

\section{Results}

The characteristics of our 6 patients are presented in Table 1 and those of the 32 previously published patients are shown in Additional file 1: Table S1 [5-8, 11, 12, 15, $16,19,20,23-25,31-35,37-40,43-46,48,49]$. The characteristics of all of the patients are summarized in Table 2.

The diagnosis of Ollier disease $(n=28)$ or Maffucci syndrome $(n=10)$ was made during childhood based on the occurrence of multiple enchondromas predominating on the articulations of the knees, hands and toes. The median age at glioma diagnosis was 25.6 years. At this time, six patients (19\%) had a previous history of chondrosarcoma. Clinical presentation consisted of a variable association of seizures (38 \%), progressive focal deficits (41 \%) and intracranial hypertension (21\%). Radiological presentation was suggestive of diffuse glioma in all of the patients (Fig. 1). Tumors were most frequently located in the frontal lobe $(54 \%)$ and in the brainstem (21\%). Contrast enhancement was present in $27 \%$ of cases. Twelve patients (32\%) had multicentric gliomas that were synchronous in eleven patients and metachronous in one patient. Multicentric gliomas were confined to the hemispheres in 8 patients and involved both the hemispheres and the brainstem in 4 patients. Two patients had gliomatosis cerebri. Ten patients (36\%) had another intracranial tumor at the time of glioma diagnosis (skull base enchondroma $n=7$, pituitary adenoma $n=2$, skull base chondrosarcoma $n=1$ ).

The glioma was histologically proven in 33 patients. Among the 5 patients without histological diagnosis, 4 patients had a typical aspect of brainstem glioma consisting of an infiltrative intra-axial T2/FLAIR hypersignal without contrast-enhancement, and 1 patient had an aspect suggestive of hemispheric low-grade glioma that was managed with initial follow-up (patient 2, Fig. 1). Histology consisted of diffuse low-grade glioma in 24 patients (73\%), anaplastic glioma in 7 patients $(21 \%)$ and glioblastoma in 2 patients $(6 \%)$. An astrocytic $(n=22$, $66 \%)$ or oligo-astrocytic phenotype $(n=8,25 \%)$ was more frequently observed than a pure oligodendroglial phenotype $(n=3,9 \%)$. IDH mutations were assessed in 8 cases (based on sequencing in 6 patients and on immunohistochemistry only in 2 patients) and detected in the tumors of 7 patients (IDH1 R132H $n=5$, IDH2 R172S $n=2)$. In the negative case, no expression of 
Table 1 Clinical, histological and molecular characteristics of our 6 patients with enchondromatosis who developed glioma

\begin{tabular}{|c|c|c|c|c|c|c|c|c|c|c|}
\hline & $\begin{array}{l}\text { Age at glioma } \\
\text { diagnosis (years) }\end{array}$ & Sex & Histology & IDH mutation & $\begin{array}{l}1 p 19 q \\
\text { co-deletion }\end{array}$ & $\begin{array}{l}\text { ATRX loss of } \\
\text { expression }\end{array}$ & Location & Multi-centric & $\begin{array}{l}\text { History of } \\
\text { chondrosarcoma }\end{array}$ & Survival (years) \\
\hline \multicolumn{11}{|c|}{ Ollier disease } \\
\hline 1 & 28 & $\mathrm{~F}$ & OAll & IDH1 R132H & No & Yes & $\mathrm{T}(n=1), \operatorname{Fr}(n=1)$ & Yes & No & $2.5+$ \\
\hline 2 & 26 & M & - & - & - & - & $\operatorname{Fr}(n=2)$ & Yes & Yes & $1+$ \\
\hline 3 & 30 & $\mathrm{~F}$ & Oll & IDH1 R132H & No & Yes & $\operatorname{Fr}(n=1), T(n=1)$ & Yes & No & 4 \\
\hline 4 & 31 & M & GBM & IDH1 R132H & No & Yes & $\operatorname{Fr}(n=2), P(n=1)$ & Yes & No & 0.75 \\
\hline 5 & 31 & $\mathrm{~F}$ & OAlll & IDH1 R132H & No & Yes & $\mathrm{Fr}$ & No & Yes & $1.5+$ \\
\hline \multicolumn{11}{|c|}{ Maffucci syndrome } \\
\hline 6 & 30 & M & OAll & IDH2 R132S & No & Yes & B & No & No & $3+$ \\
\hline
\end{tabular}

IDH1 R132H was detected on immunohistochemistry, but other $I D H$ mutations were not assessed [38]. In two patients (patient 5 and a previously reported patient [34]) the presence of an $I D H$ mutation could be analyzed in both the glioma and a skeletal tumor and the same mutation (IDH1 R132H in patient 5 and IDH2 R172S in [34]) was identified in these tumors. Since none of our patients underwent a biopsy of more than one glioma, the analysis of $I D H$ mutations in different gliomas from the same patient could not be performed. No 1p/19q codeletion was identified in the 6 cases in which it was assessed (oligo-astrocytoma $n=4$, oligodendroglioma $n=1$, glioblastoma $n=1$ ). TP53 expression was studied in 6 patients and found to be expressed in 5

Table 2 Summary of the clinical, histological and molecular characteristics of Ollier disease (OD), Maffucci syndrome (MS), enchondromatosis (OD + MS) -present series and literature- and sporadic IDH mutated glioma patients

\begin{tabular}{|c|c|c|c|c|c|}
\hline & Ollier disease & Maffucci syndrome & Enchondro-matosis & $\begin{array}{l}\text { Sporadic IDH mutated } \\
\text { gliomas }\end{array}$ & $\begin{array}{l}\text { Enchondro-matosis versus sporadic } \\
\text { IDH mutated glioma } P \text {-value }\end{array}$ \\
\hline N & 28 & 10 & 38 & 159 & \\
\hline $\mathrm{N}$ of gliomas & 45 & 12 & 57 & 161 & \\
\hline Sex ratio (M/F) & $18 / 10$ & $7 / 3$ & $25 / 13$ & $91 / 68$ & 0.4 \\
\hline Median age (years, range) & $24.7(6-46)$ & $28.1(17-39)$ & $25.6(6-46)$ & $44(6-81)$ & $<0.0001$ \\
\hline \multicolumn{6}{|l|}{ Histology } \\
\hline Grade II & $68 \%(17 / 25)$ & $87.5 \%(7 / 8)$ & $72.7 \%(24 / 33)$ & $47 \%(75 / 159)$ & 0.01 \\
\hline Grade III & $24 \%(6 / 25)$ & $12.5 \%(1 / 8)$ & $21.2 \%(7 / 33)$ & $39 \%(62 / 159)$ & 0.05 \\
\hline Grade IV & $8 \%(2 / 25)$ & & $6.1 \%(2 / 33)$ & $14 \%(22 / 159)$ & 0.4 \\
\hline \multicolumn{6}{|l|}{ Location } \\
\hline Frontal & $53.4 \%(24 / 45)$ & $58 \%(7 / 12)$ & $54.1 \%(31 / 57)$ & $67,1 \%(108 / 161)$ & 0.1 \\
\hline Parietal & $4.4 \%(2 / 45)$ & & $3.6 \%(2 / 57)$ & $7.5 \%(12 / 161)$ & 0.4 \\
\hline Insular & $4.4 \%(2 / 45)$ & & $3.6 \%(2 / 57)$ & $5,6 \%(9 / 161)$ & 0.7 \\
\hline Temporal & $13.3 \%(6 / 45)$ & & $10.5 \%(6 / 57)$ & $11.8 \%(19 / 161)$ & 1 \\
\hline Occipital & $2.2 \%(1 / 45)$ & & $1.8 \%(1 / 57)$ & $1.9 \%(3 / 161)$ & 1 \\
\hline Brainstem & $15.7 \%(7 / 45)$ & $42 \%(5 / 12)$ & $21 \%(12 / 57)$ & $0.6 \%(1 / 161)$ & $<0.0001$ \\
\hline Gliomatosis & $4.4 \%(2 / 45)$ & & $3.6 \%(2 / 57)$ & $5 \%(8 / 161)$ & 1 \\
\hline Thalamic & $2.2 \%(1 / 45)$ & & $1.8 \%(1 / 57)$ & $0.6 \%(1 / 161)$ & 1 \\
\hline Multicentric & $39.2 \%(11 / 28)$ & $10 \%(1 / 10)$ & $31.6 \%(12 / 38)$ & $1.3 \%(2 / 159)$ & $<0.0001$ \\
\hline IDH mutation & $83 \%(5 / 6)$ & $100 \%(2 / 2)$ & $87.5 \%(7 / 8)$ & $100 \%$ & - \\
\hline 1p/19q co-deletion & $0 \%(0 / 5)$ & $0 \%(0 / 1)$ & $0 \%(0 / 6)$ & $48 \%(59 / 123)$ & 0.03 \\
\hline Other intracranial Tumor & $25 \%(7 / 21)$ & $43 \%(3 / 7)$ & $36 \%(10 / 28)$ & $1.9 \%(3 / 159)$ & $<0.0001$ \\
\hline History of chondrosarcoma & $12.5 \%(3 / 24)$ & $42.8 \%(3 / 7)$ & $19.3 \%(6 / 31)$ & $0 \%$ & $<0.0001$ \\
\hline
\end{tabular}



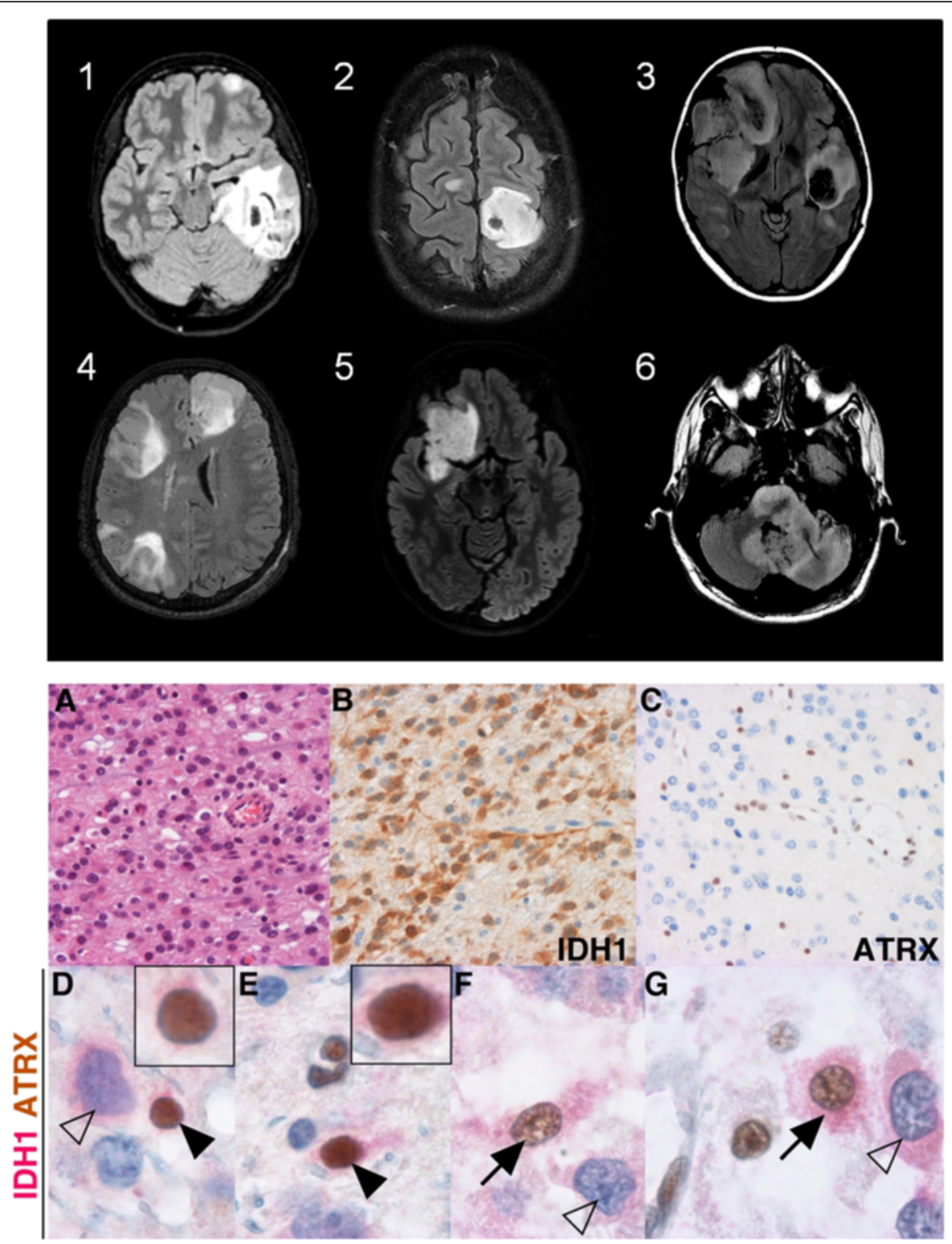

Fig. $1 \mathrm{MRI}$ characteristics of the diffuse gliomas in the 6 new enchondromatosis patients and double staining with anti-IDH1R132H and anti-ATRX antibodies. Top: MRI findings of patient 1 to patient 6 at diagnosis (axial T2/fluid-attenuated inversion recovery (FLAIR) sequences) demonstrating multicentric tumors in patients 1, 2, 3 and 4. Bottom: histological characteristics of the recurrent tumor of patient 3. a Hematoxylin eosin staining demonstrating an anaplastic glioma. b IDH1 R132H expression (brown signal). c Diffuse loss of ATRX expression in tumor cells and maintained expression (brown signal) in endothelial cells. $\mathbf{d}$-g) Double staining demonstrating rare cells with a normal oligodendrocyte (black arrowheads) or astrocyte (black arrows) morphology expressing both IDH1 R132H (red signal) and ATRX (brown signal) (inserts showing same cells at higher magnification) and tumor cells with abnormal morphology and expressing IDH1 R132H but not ATRX (white arrows)

patients. In an additional patient, sequencing demonstrated missenses TP53 mutations [34]. ATRX expression was studied in 5 patients. A homogeneous loss of expression was observed in 4 patients and a heterogeneous loss of expression in 1 patient (patient 3). Genomic profiles of the tumors were obtained for 2 patients; one patient had an isolated $\mathrm{LOH}$ of the $17 \mathrm{p}$ region covering the TP53 locus (patient 3 ), and the other patient had a LOH of chromosome 9 associated with partial losses of chromosomes $14 \mathrm{q}$ and $15 \mathrm{q}$ and a partial gain of chromosome 11q (patient 5). In patient 3, double staining with anti-ATRX and antiIDH1 R132H antibodies identified: (i) areas with maintained ATRX expression in tumor cells, and (ii) areas with diffuse loss of ATRX expression in tumors cells. In these last areas, some very rare IDH1 R132H 
and ATRX positive cells with a normal morphology were observed (Fig. 1). Treatment consisted of surgical resection (46\%), radiotherapy $(80 \%)$ and or chemotherapy (42\%). The median survival after glioma diagnosis was 5 years.

Independent of histology and 1p/19q co-deletion status, gliomas in enchondromatosis patients were diagnosed at an earlier age than sporadic IDH mutated gliomas (25.6 years versus 44 years, $p<0.001$, Fig. 2 ). In addition, they were more frequently multicentric ( $32 \%$ versus $1 \%$, $p<0.001)$, more frequently involved the brainstem (21\% versus $1 \%, p<0.001)$ and were not associated with a $1 \mathrm{p} /$ $19 \mathrm{q}$ co-deletion $(0 / 6$ versus $59 / 123, p=0.03)$.

\section{Discussion}

The high rate of multicentric gliomas, the identification of $I D H$ mutations in all of the gliomas in which it could be fully assessed and the identical $I D H$ mutations found in both the glioma and the skeletal tumor of two patients strongly suggest that, in most cases, similar to cartilaginous tumors, the development of gliomas in enchondromatosis patients results from somatic $I D H$ mosaicism. The very rare IDH1 R132H and ATRX positive cells with a normal morphology found in patient 3 may further support this hypothesis. Consistent with the demonstration of occasional IDH mutated cells in the normal bone, blood and bone marrow of some enchondromatosis patients, we speculate that these

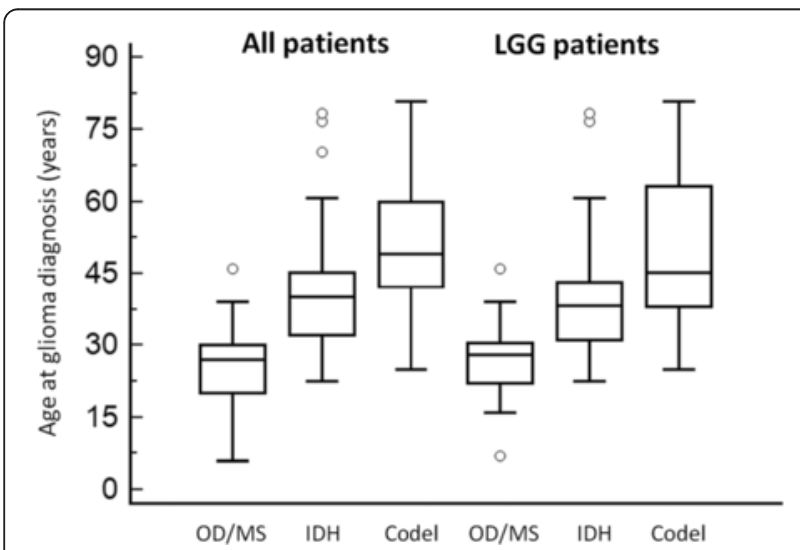

Fig. 2 Age at glioma in patients with enchondromatosis and sporadic IDH mutated gliomas according to grade and $1 \mathrm{p} / 19 \mathrm{q}$ co-deletion. $Y$ axis: age at glioma diagnosis (years). $X$ axis: OD/MS: enchondromatosis patients with glioma, IDH: patients with sporadic IDH mutated gliomas without 1p/19q co-deletion, Codel: patients with sporadic IDH mutated gliomas with $1 \mathrm{p} / 19 \mathrm{q}$ co-deletion. Median age at glioma diagnosis, was lower in OD/MS than in IDH patients (25.6 vs 41 years, $p<0.001$ ) and in IDH than in Codel patients (41 years vs 50.8 years, $p<0.001$ ). The difference remained significant when taking into account only LGG (OD/MS vs IDH patients: 26.9 vs 39 years, $p<0.001$; IDH vs Codel patients: 39 vs 49 years, $p=0.01$ ) cells may correspond to normal glial cells with $I D H$ mutations [3, 36]. However, this observation must be taken with caution since morphology is subjective and ATRX expression can be heterogeneous [41].

IDH mutations are considered to be the earliest oncogenic events in the majority of lower grade gliomas [10]. In animal models, $I D H$ mutations have been shown to be sufficient to induce enchondromas and chondrosarcomas $[17,29]$. To our knowledge, this demonstration has not been previously reported for gliomas, but the occurrence of gliomas in enchondromatosis patients, in whom $I D H$ mutations are thought to occur as an early post-zygotic event suggests that $I D H$ mutations can initiate gliomagenesis $[3,36]$. In addition, the median age at glioma diagnosis in these patients (25 years) suggests that $I D H$ driven gliomagenesis is a very slow process. In contrast to enchondromas, however, IDH mutation alone is probably not sufficient to induce gliomas. Additional alterations, such as ATRX and TP53 mutations, are necessary [10]. Consistently, Moriya et al. identified a TP53 mutation in the glioma but not in an enchondroma of their patient, though both lesions shared the same $I D H 2$ mutation [34]. This could explain why enchondromas appear much earlier than gliomas in enchondromatosis patients.

It is unknown why only a small percentage of enchondromatosis patients (approximately $5 \%$ ) develop gliomas [45]. It could be related to a variable distribution and proportion of mutated cells within the brain, to the fact that only a small percentage of $I D H$ mutated glial cells acquire additional alterations, or to the type of $I D H \mathrm{mu}$ tation present. In cartilaginous tumors of enchondromatosis patients the IDH1 R132C mutation is more frequent than the $I D H 1 \mathrm{R} 132 \mathrm{H}$ mutation (70 and $15 \%$, respectively) $[3,36]$, while the $I D H 1 \mathrm{R} 132 \mathrm{H}$ mutation is the most frequent mutation (90\%) in sporadic $I D H \mathrm{mu}$ tated gliomas [50]. Enchondromatosis patients with an IDH1 R132H mutation could have a higher risk of developing gliomas than patients with an IDH1 R132C mutation. In our series, an IDH1 R132H mutation was present in 5 out of the 7 enchondromatosis patients who developed diffuse glioma.

Not surprisingly, like sporadic IDH mutated gliomas, enchondromatosis gliomas were frequently located in the frontal lobe and were more frequently diffuse low-grade or anaplastic gliomas than glioblastomas. However, they differed from sporadic $I D H$-mutated gliomas in several aspects. First, they were diagnosed at an earlier age. This difference could be explained by the fact that in sporadic $I D H$-mutated gliomas, the $I D H$ mutation is acquired later than in enchondromatosis patients. Second, enchondromatosis gliomas, compared to sporadic IDH mutated gliomas, more frequently involved the brainstem, which may also be related to an earlier origin of enchondromatosis 
gliomas (i.e., during the first years of life, which is a period associated with the development of infratentorial gliomas). Since both H3-K27M mutations (which are present in most cases of children brainstem gliomas) and $I D H$ mutations alter histone methylation, brainstem gliomas may therefore require histone modification of precursor cells at an early stage of development $[9,28,30]$. This particularity could help explaining why early acquisition of $I D H$ mutations mimics the regional preference of $\mathrm{H} 3-\mathrm{K} 27 \mathrm{M}$ mutated gliomas and why gliomas in that location are rare in adults. At last, none of the 6 enchondromatosis gliomas that could be tested were associated with a $1 \mathrm{p} / 19 \mathrm{q}$ codeletion. This observation needs confirmation in a larger series, however, again it could be related to a different timing of oncogenesis because the $1 \mathrm{p} / 19 \mathrm{q}$ co-deletion is virtually absent in pediatric gliomas [42]. Consistently, in the present series, as in previously reported series, patients with $1 \mathrm{p} / 19 \mathrm{q}$ co-deleted gliomas were older at diagnosis than those with $I D H$ mutated non $1 \mathrm{p} / 19 \mathrm{q}$ co-deleted gliomas [13].

Finally, multicentric gliomas were much more frequent in enchondromatosis than in sporadic $I D H$-mutated gliomas. Multicentric gliomas (i.e., with no apparent continuity between tumors) account for 2 to $5 \%$ of sporadic gliomas [1]. Their oncogenesis is debated. In some cases, evidence has been provided that the multiple tumors actually originated from the same clone [1]. However, the multicentric presentation of gliomas reported in patients with inherited glioma predisposition and the high incidence of systemic cancers reported in patients with multicentric gliomas also suggest that multicentric gliomas may originate from different clones in patients who have inherited genetic alterations predisposing them to gliomas $[4,27]$. Our study shows that somatic mosaicism might be another mechanism leading to the development of multicentric gliomas. It remains to be determined whether somatic IDH mosaicism might be responsible for the occurrence of multicentric gliomas in patients without enchondromatosis.

\section{Conclusions}

In addition to its retrospective design and its small sample-size, limitations of the present study include the limited number of patients in whom molecular characterization was possible, the absence of comprehensive molecular analysis and the absence of $I D H \mathrm{mu}-$ tation assessment in several gliomas from the same patient. Nevertheless, the analysis of glioma characteristics in patients with enchondromatosis sheds new light on $I D H$ driven gliomagenesis. It provides evidence that the $I D H$ mutation can initiate gliomagenesis and that the timing of $I D H$ mutation acquisition might influence the location and molecular characteristics of gliomas.

\section{Additional file}

Additional file 1: Table S1. The characteristics of those of the 32 previously published patients. (XLSX $15 \mathrm{~kb}$ )

\section{Competing interests}

The authors declare that they have no competing interests.

\section{Authors' contributions}

CB: design and conceptualization of the study and data analysis and interpretation. LT: data acquisition, analysis and interpretation. DP: data acquisition, analysis and interpretation. FB: data acquisition, analysis and interpretation. EV: data acquisition, analysis and interpretation. HL: data acquisition, analysis and interpretation. DM: data acquisition, analysis and interpretation. CD: data acquisition, analysis and interpretation. JH: data analysis and interpretation and manuscript revision regarding intellectual content. MS: design and conceptualization of the study, data analysis and interpretation, and manuscript revision regarding intellectual content. FD: design and conceptualization of the study, data analysis and interpretation, and manuscript revision regarding intellectual content. All authors read and approved the final manuscript.

\section{Acknowledgements}

We thank Andry Ralitera for immunolabeling techniques.

Study funding

No targeted funding reported.

\section{Disclosures}

All authors report no disclosures relevant to the manuscript.

\section{Author details}

${ }^{1}$ Hospices Civils de Lyon, Hôpital Neurologique, Service de Neuro-oncologie, 59 Bvd Pinel, 69394 Lyon, Cedex, France. ${ }^{2}$ Université Claude Bernard Lyon 1, Lyon, France. ${ }^{3}$ Department of Cancer Cell Plasticity, Cancer Research Centre of Lyon, INSERM U1052, CNRS UMR5286, Lyon, France. ${ }^{4}$ AP-HP, Groupe Hospitalier Pitié-Salpêtrière, Service de neurologie 2-Mazarin, Paris, France. ${ }^{5}$ AP-HP, Hôpitaux Universitaires Pitié Salpêtrière - Charles Foix, Laboratoire de Neuropathologie R. Escourolle, Paris, France. ${ }^{6}$ Sorbonne Universités, UPMC Univ Paris 06, Centre de recherche de l'Institut de Cerveau et de la Moelle Epinière (CRICM), UMR 975, Paris, France. ${ }^{7}$ INSERM U975, Paris, France. ${ }^{8}$ CNRS, UMR 7225, Paris, France. ${ }^{9}$ Centre Eugène Marquis, Medical Oncology, Rennes, France. ${ }^{10}$ Université de Bordeaux, Neurosurgery Department GH Pellegrin, Bordeaux, France. ${ }^{11}$ Hospices Civils de Lyon, Groupe Hospitalier Est, Service de Neuropathologie, Lyon, France. ${ }^{12}$ Lyon's Neurosciences Research Center (CRNL) INSERM U1028, CNRS UMR5292, Lyon, France.

Received: 16 March 2016 Accepted: 16 March 2016

Published online: 31 March 2016

\section{References}

1. Akimoto J, Sasaki H, Haraoka R, Nakajima N, Fukami S, Kohno M. Case of radiologically multicentric but genetically identical multiple glioblastomas. Brain Tumor Pathol. 2014;31:113-7. doi:10.1007/s10014-013-0157-x.

2. Amary MF, Bacsi K, Maggiani F, Damato S, Halai D, Berisha F, Pollock R, O'Donnell P, Grigoriadis A, Diss T, Eskandarpour M, Presneau N, Hogendoorn PC, Futreal A, Tirabosco R, Flanagan AM. IDH1 and IDH2 mutations are frequent events in central chondrosarcoma and central and periosteal chondromas but not in other mesenchymal tumours.

J Pathol. 2011:224:334-43. doi:10.1002/path.2913.

3. Amary MF, Damato S, Halai D, Eskandarpour M, Berisha F, Bonar F, McCarthy S, Fantin VR, Straley KS, Lobo S, Aston W, Green CL, Gale RE, Tirabosco R, Futreal A, Campbell P, Presneau N, Flanagan AM. Ollier disease and Maffucci syndrome are caused by somatic mosaic mutations of IDH1 and IDH2. Nat Genet. 2011;43:1262-5. doi:10.1038/ng.994. ng.994 [pii].

4. Aure K, Laigle-Donadey F, Kaloshi G, Amiel-Benouaich A, Sanson M. Multiple gliomas: clinical studies and pathophysiological hypothesis]. Rev Neurol (Paris). 2006;162:845-51. doi:MDOI-RN-09-2006-162-8-9-0035-3787-101019200602725. 
5. Balcer LJ, Galetta SL, Cornblath WT, Liu GT. Neuro-ophthalmologic manifestations of Maffucci's syndrome and Ollier's disease. J Neuroophthalmol. 1999;19:62-6.

6. Bathla G, Gupta S, Ong CK. Multifocal intracranial astrocytoma in a pediatric patient with Ollier disease. Indian J Radiol Imaging. 2012;22:58-62. doi:10.4103/0971-3026.95406.

7. Becker W, Thron A. Dyschondroplasia with glioma of the brain. Third histologically verified case (author's transl). Arch Orthop Trauma Surg. 1979; 93:141-4.

8. Bendel CJ, Gelmers HJ. Multiple enchondromatosis (Ollier's disease) complicated by malignant astrocytoma. Eur J Radiol. 1991;12:135-7. doi: 0720-048X(91)90115-C.

9. Bender S, Tang Y, Lindroth AM, Hovestadt V, Jones DT, Kool M, Zapatka M, Northcott PA, Sturm D, Wang W, Radlwimmer B, Hojfeldt JW, Truffaux N, Castel D, Schubert S, Ryzhova M, Seker-Cin H, Gronych J, Johann PD, Stark S, Meyer J, Milde T, Schuhmann M, Ebinger M, Monoranu CM, Ponnuswami A, Chen S, Jones C, Witt O, Collins VP, von Deimling A, Jabado N, Puget S, Grill J, Helin K, Korshunov A, Lichter P, Monje M, Plass C, Cho YJ, Pfister SM. Reduced H3K27me3 and DNA hypomethylation are major drivers of gene expression in K27M mutant pediatric high-grade gliomas. Cancer Cell. 2013; 24:660-72. doi:10.1016/j.ccr.2013.10.006. S1535-6108(13)00455-8.

10. Brat DJ, Verhaak RG, Aldape KD, Yung WK, Salama SR, Cooper LA, et al. Comprehensive, Integrative Genomic Analysis of Diffuse Lower-Grade Gliomas. N Engl J Med. 2015;372:2481-98. doi:10.1056/NEJMoa1402121.

11. Chang S, Prados MD. Identical twins with Ollier's disease and intracranial gliomas: case report. Neurosurgery. 1994;34:903-6. discussion 906.

12. Cremer H, Gullotta F, Wolf L. The Mafucci-Kast Syndrome. Dyschondroplasia with hemangiomas and frontal lobe astrocytoma. J Cancer Res Clin Oncol. 1981;101:231-7.

13. Eckel-Passow JE, Lachance DH, Molinaro AM, Walsh KM, Decker PA, Sicotte H, Pekmezci M, Rice T, Kosel ML, Smirnov IV, Sarkar G, Caron AA, Kollmeyer TM, Praska CE, Chada AR, Halder C, Hansen HM, McCoy LS, Bracci PM, Marshall R, Zheng S, Reis GF, Pico AR, O'Neill BP, Buckner JC, Giannini C, Huse JT, Perry A, Tihan T, Berger MS, Chang SM, Prados MD, Wiemels J, Wiencke JK, Wrensch MR, Jenkins RB. Glioma Groups Based on 1p/19q, IDH, and TERT Promoter Mutations in Tumors. N Engl J Med. 2015;372:2499-508. doi:10.1056/NEJMoa1407279.

14. Flavahan WA, Drier Y, Liau BB, Gillespie SM, Venteicher AS, StemmerRachamimov AO, Suva ML, Bernstein BE. Insulator dysfunction and oncogene activation in IDH mutant gliomas. Nature. 2016;529:110-4. doi:10. 1038/nature16490. nature16490 [pii].

15. Frappaz D, Ricci AC, Kohler R, Bret P, Mottolese C. Diffuse brain stem tumor in an adolescent with multiple enchondromatosis (Ollier's disease). Childs Nerv Syst. 1999;15:222-5. doi:10.1007/s003810050377.

16. Goto H, Ito Y, Hirayama A, Sakamoto T, Kowada M. Maffucci's syndrome associated with primary brain tumor: report of a case. No Shinkei Geka. 1987;15:971-5

17. Hirata M, Sasaki M, Cairns RA, Inoue S, Puviindran V, Li WY, Snow BE, Jones LD, Wei Q, Sato S, Tang YJ, Nadesan P, Rockel J, Whetstone H, Poon R, Weng A, Gross S, Straley K, Gliser C, Xu Y, Wunder J, Mak TW, Alman BA. Mutant IDH is sufficient to initiate enchondromatosis in mice. Proc Natl Acad Sci U S A. 2015;112:2829-34. doi:10.1073/pnas.1424400112. 1424400112 [pii].

18. Hoang-Xuan K, Capelle L, Kujas M, Taillibert S, Duffau H, Lejeune J, Polivka M, Criniere E, Marie Y, Mokhtari K, Carpentier AF, Laigle F, Simon JM, Cornu P, Broet P, Sanson M, Delattre JY. Temozolomide as initial treatment for adults with low-grade oligodendrogliomas or oligoastrocytomas and correlation with chromosome $1 p$ deletions. J Clin Oncol. 2004;22:3133-8.

19. Hofman S, Heeg M, Klein JP, Krikke AP. Simultaneous occurrence of a supraand an infratentorial glioma in a patient with Ollier's disease: more evidence for non-mesodermal tumor predisposition in multiple enchondromatosis. Skeletal Radiol. 1998;27:688-91.

20. Hori K, Matsumine A, Niimi R, Maeda M, Uchida K, Nakamura T, Sudo A. Diffuse gliomas in an adolescent with multiple enchondromatosis (Ollier's disease). Oncol Lett. 2010;1:595-7. doi:10.3892/ol_00000105. ol-01-04-0595 [pii].

21. Houillier C, Wang X, Kaloshi G, Mokhtari K, Guillevin R, Laffaire J, Paris S, Boisselier B, Idbaih A, Laigle-Donadey F, Hoang-Xuan K, Sanson M, Delattre JY. IDH1 or IDH2 mutations predict longer survival and response to temozolomide in low-grade gliomas. Neurology. 2010;75:1560-6. doi:75/17/ 1560 [pii] 10.1212/WNL.0b013e3181f96282.
22. Idbaih A, Ducray F, Dehais C, Courdy C, Carpentier C, de Bernard S, UroCoste E, Mokhtari K, Jouvet A, Honnorat J, Chinot O, Ramirez C, Beauchesne P, Benouaich-Amiel A, Godard J, Eimer S, Parker F, Lechapt-Zalcman E, Colin P, Loussouarn D, Faillot T, Dam-Hieu P, Elouadhani-Hamdi S, Bauchet L, Langlois O, Le Guerinel C, Fontaine D, Vauleon E, Menei P, Fotso MJ, Desenclos C, Verelle P, Ghiringhelli F, Noel G, Labrousse F, Carpentier A, Dhermain F, Delattre JY, Figarella-Branger D. SNP array analysis reveals novel genomic abnormalities including copy neutral loss of heterozygosity in anaplastic oligodendrogliomas. PLoS One. 2012;7, e45950. doi:10.1371/ journal.pone.0045950. PONE-D-12-17593 [pii].

23. Jirarattanaphochai K, Jitpimolmard S. Maffucci's syndrome with frontal lobe astrocytoma. J Med Assoc Thai. 1990;73:288-93.

24. Khan SH, Rather TA, Koul PA, Makhdoomi R, Bhat AR, Malik D, Manohar R. Bone scintigraphy in Ollier's disease: A rare case report. Indian J Nucl Med. 2013;28:226-9. doi:10.4103/0972-3919.121968.

25. Koc F, Koc Z. Ollier Disease Anaplastic Mixed Oligoastrocytoma A Rare Association With Brain Tumors. Neurosurgery Q. 2006;16:195-7.

26. Koivunen P, Lee S, Duncan CG, Lopez G, Lu G, Ramkissoon S, Losman JA, Joensuu P, Bergmann U, Gross S, Travins J, Weiss S, Looper R, Ligon KL, Verhaak RG, Yan H, Kaelin WG, Jr. Transformation by the (R)-enantiomer of 2-hydroxyglutarate linked to EGLN activation. Nature. 2012;483:484-8. doi:10.1038/nature10898. nature10898.

27. Kyritsis AP, Bondy ML, Rao JS, Sioka C. Inherited predisposition to glioma. Neuro Oncol. 2010;12:104-13. doi:10.1093/neuonc/nop011. nop011 [pii].

28. Lewis PW, Muller MM, Koletsky MS, Cordero F, Lin S, Banaszynski LA, Garcia BA, Muir TW, Becher OJ, Allis CD. Inhibition of PRC2 activity by a gain-offunction H3 mutation found in pediatric glioblastoma. Science. 2013;340: 857-61. doi:10.1126/science.1232245. science.1232245.

29. Lu C, Venneti S, Akalin A, Fang F, Ward PS, Dematteo RG, Intlekofer AM, Chen C, Ye J, Hameed M, Nafa K, Agaram NP, Cross JR, Khanin R, Mason CE, Healey JH, Lowe SW, Schwartz GK, Melnick A, Thompson CB. Induction of sarcomas by mutant IDH2. Genes Dev. 2013;27:1986-98. doi:10.1101/gad. 226753.113

30. Lu C, Ward PS, Kapoor GS, Rohle D, Turcan S, Abdel-Wahab O, Edwards CR, Khanin R, Figueroa ME, Melnick A, Wellen KE, O'Rourke DM, Berger SL, Chan TA, Levine RL, Mellinghoff IK, Thompson CB. IDH mutation impairs histone demethylation and results in a block to cell differentiation. Nature. 2012;483: 474-8. doi:10.1038/nature10860. nature10860 [pii].

31. Mahafza WS. Multiple enchondromatosis Ollier's disease with two primary brain tumors. Saudi Med J. 2004;25:1261-3. doi:20040107.

32. Mellon CD, Carter JE, Owen DB. Ollier's disease and Maffucci's syndrome: distinct entities or a continuum. Case report: enchondromatosis complicated by an intracranial glioma. J Neurol. 1988;235:376-8.

33. Mitchell RA, Ye JM, Mandelstam S, Lo P. Gliomatosis cerebri in a patient with Ollier disease. J Clin Neurosci. 2011;18:1564-6. doi:10.1016/j.jocn.2011.03.025.

34. Moriya K, Kaneko MK, Liu X, Hosaka M, Fujishima F, Sakuma J, Ogasawara S, Watanabe M, Sasahara Y, Kure S, Kato Y. IDH2 and TP53 mutations are correlated with gliomagenesis in a patient with Maffucci syndrome. Cancer Sci. 2014;105:359-62. doi:10.1111/cas.12337.

35. Palacios E, Valvassori G, D'Antonio M. Enchondroma of the petrous bone and parasellar area in Maffucci's syndrome. Ear Nose Throat J. 2001;80:75.

36. Pansuriya TC, van Eijk R, d'Adamo P, van Ruler MA, Kuijjer ML, Oosting J, Cleton-Jansen AM, van Oosterwijk JG, Verbeke SL, Meijer D, van Wezel T, Nord KH, Sangiorgi L, Toker B, Liegl-Atzwanger B, San-Julian M, Sciot R, Limaye N, Kindblom LG, Daugaard S, Godfraind C, Boon LM, Vikkula M, Kurek KC, Szuhai K, French PJ, Bovee JV. Somatic mosaic IDH1 and IDH2 mutations are associated with enchondroma and spindle cell hemangioma in Ollier disease and Maffucci syndrome. Nat Genet. 2011:43:1256-61. doi:10.1038/ng.1004. ng.1004 [pii].

37. Patt $\mathrm{S}$, Weigel K, Mayer HM. A case of dyschondroplasia associated with brain stem glioma: diagnosis by stereotactic biopsy. Neurosurgery. 1990;27: 487-91.

38. Pearce P, Robertson T, Ortiz-Gomez JD, Rajah T, Tollesson G. Multifocal supratentorial diffuse glioma in a young patient with Ollier disease. J Clin Neurosci. 2012;19:477-8. doi:10.1016/j.jocn.2011.06.019.

39. Ranger A, Szymczak A, Hammond RR, Zelcer S. Pediatric thalamic glioblastoma associated with Ollier disease (multiple enchondromatosis): a rare case of concurrence. J Neurosurg Pediatr. 2009:4:363-7. doi:10.3171/ 2009.5.PEDS08422.

40. Rawlings 3rd CE, Bullard DE, Burger PC, Friedman AH. A case of Ollier's disease associated with two intracranial gliomas. Neurosurgery. 1987;21:400-3. 
41. Reuss DE, Sahm F, Schrimpf D, Wiestler B, Capper D, Koelsche C, Schweizer L, Korshunov A, Jones DT, Hovestadt V, Mittelbronn M, Schittenhelm J, Herold-Mende C, Unterberg A, Platten M, Weller M, Wick W, Pfister SM, von Deimling A. ATRX and IDH1-R132H

immunohistochemistry with subsequent copy number analysis and IDH sequencing as a basis for an "integrated" diagnostic approach for adult astrocytoma, oligodendroglioma and glioblastoma. Acta Neuropathol. 2015;129:133-46. doi:10.1007/s00401-014-1370-3.

42. Rodriguez FJ, Tihan T, Lin D, McDonald W, Nigro J, Feuerstein B, Jackson S, Cohen K, Burger PC. Clinicopathologic features of pediatric oligodendrogliomas: a series of 50 patients. Am J Surg Pathol. 2014;38: 1058-70. doi:10.1097/PAS.0000000000000221.

43. Ruivo J, Antunes JL. Maffucci syndrome associated with a pituitary adenoma and a probable brainstem tumor. J Neurosurg. 2009;110:363-8. doi:10.3171/ 2008.8.JNS08150.

44. Sato K, Hayashi M, Katsumura H, Ishii H, Kubota T. A case of Maffucci's syndrome with brain-stem tumor. No To Shinkei. 1989:41:631-4.

45. Schwartz HS, Zimmerman NB, Simon MA, Wroble RR, Millar EA, Bonfiglio M. The malignant potential of enchondromatosis. J Bone Joint Surg Am. 1987; 69:269-74.

46. Simsek S, Seckin H, Belen D, Erekul S. Ollier' s Disease With Intracranial Glioma. TÜrk NörosirÜrji Dergisi. 2002;12:66-9.

47. Turcan S, Rohle D, Goenka A, Walsh LA, Fang F, Yilmaz E, Campos C, Fabius AW, Lu C, Ward PS, Thompson CB, Kaufman A, Guryanova O, Levine R, Heguy A, Viale A, Morris LG, Huse JT, Mellinghoff IK, Chan TA. IDH1 mutation is sufficient to establish the glioma hypermethylator phenotype. Nature. 2012;483:479-83. doi:10.1038/nature10866. nature10866 [pii].

48. van Nielen KM, de Jong BM. A case of Ollier's disease associated with two intracerebral low-grade gliomas. Clin Neurol Neurosurg. 1999;101:106-10. doi:S0303846798000729.

49. Walid MS, Troup EC. Cerebellar anaplastic astrocytoma in a teenager with Ollier Disease. J Neurooncol. 2008;89:59-62. doi:10.1007/s11060-008-9583-8.

50. Yan H, Parsons DW, Jin G, McLendon R, Rasheed BA, Yuan W, Kos I, BatinicHaberle I, Jones S, Riggins GJ, Friedman H, Friedman A, Reardon D, Herndon J, Kinzler KW, Velculescu VE, Vogelstein B, Bigner DD. IDH1 and IDH2 Mutations in Gliomas. N Engl J Med. 2009;360:765-73.

\section{Submit your next manuscript to BioMed Central and we will help you at every step:}

- We accept pre-submission inquiries

- Our selector tool helps you to find the most relevant journal

- We provide round the clock customer support

- Convenient online submission

- Thorough peer review

- Inclusion in PubMed and all major indexing services

- Maximum visibility for your research

Submit your manuscript at www.biomedcentral.com/submit 